\title{
The novel cytokine interleukin-36 $\alpha$ is expressed in psoriatic and rheumatoid arthritis synovium
}

\author{
Silke Frey, ${ }_{1}^{1}$ Anja Derer, ${ }^{1}$ Maria-Elena Messbacher, ${ }^{1}$ Dominique L P Baeten, ${ }^{2}$ \\ Serena Bugatti, ${ }^{3}$ Carlomaurizio Montecucco, ${ }^{3}$ Georg Schett, ${ }^{1}$ Axel J Hueber ${ }^{1}$
}

Handling editor Tore K Kvien

- Additional material is published online only. To view please visit the journal online (http://dx.doi.org/10.1136/ annrheumdis-2012-202264).

${ }^{1}$ Department of Internal Medicine 3 and Institute for Clinical Immunology, University Hospital of Erlangen-

Nuremberg, Erlangen, Germany

${ }^{2}$ Department of Clinical Immunology and

Rheumatology, Academic Medical Center/University of

Amsterdam, Amsterdam, The Netherlands

${ }^{3}$ Division of Rheumatology, University of Pavia, IRCCS Policlinico San Matteo

Foundation, Pavia, Italy

\section{Correspondence to} Dr Axel J Hueber, Department of Internal Medicine 3 and Institute for Clinical Immunology, University Hospital of ErlangenNuremberg, Ulmenweg 18, Erlangen 90154, Germany; axel.hueber@uk-erlangen.de

Received 26 June 2012 Revised 30 November 2012 Accepted 2 December 2012 Published Online First 25 December 2012

\section{ABSTRACT}

Background Interleukin (IL)-36 $\alpha$ is a recently described member of the IL-1 cytokine family with pro-inflammatory and clearly pathogenic properties in psoriasis.

Objective To determine the IL-36 $\alpha$ expression in psoriatic arthritis (PsA) compared to rheumatoid arthritis (RA) and osteoarthritis (OA).

Methods Synovial tissues obtained from arthritis patients were stained for IL-36 $\alpha$, IL-36 receptor (IL-36R) and IL-36R antagonist (IL-36Ra) by immunohistochemistry and immunofluorescence. Lysates were examined for IL$36 \alpha$ by western blot analysis. Synovial fibroblasts (FLS) cultured in the presence of IL-36 $\alpha$ were assayed for cytokine expression by quantitative real time PCR and multiplex assay. IL-36 $\alpha$-induced signal transduction in FLS was analysed by immunoblotting.

Results Expression of IL-36R and its ligands IL-36 $\alpha$ and IL-36Ra was detected in the synovial lining layer and cellular infiltrates of patients with inflammatory arthritis. IL-36 $\alpha$ was expressed significantly higher in PsA and RA than in OA synovium. CD138-positive plasma cells were identified as the main cellular source of IL-36 $\alpha$. No differences were observed for the expression of IL-36R and IL-36Ra between PsA, RA and OA. Functionally, IL$36 \alpha$ induced the expression of IL-6 and IL-8 in FLS through p38/NFkB activation.

Conclusions IL-36 $\alpha$ is up-regulated in PSA and RA synovium, expressed by tissue plasma cells and leads to IL-6 and IL-8 production by synovial fibroblasts. Hence, IL$36 \alpha$ links plasma cells to inflammatory cytokine production by FLS and may represent a key link between autoimmunity and the induction of synovitis.

\section{INTRODUCTION}

The recently discovered cytokine interleukin (IL)-36 $\alpha$ (IL-1F6) and its antagonist IL-36Ra (IL-1F5) are members of the IL-1 cytokine family. ${ }^{1}$ Little is known regarding the expression pattern of these cytokines. Expression of IL-36 $\alpha$ is restricted, whereas the IL-36 receptor (IL-36R) appears to be more widely expressed. High expression of IL-36 $\alpha$ messenger RNA was particularly found in epithelial tissues and keratinocytes. In addition, initial studies demonstrated that IL-36 $\alpha$ mRNA is expressed in leukocytes. $^{2}$ In contrast, IL-36R is primarily expressed by stromal cells, such as fibroblasts, as well as keratinocytes. ${ }^{3}{ }^{4}$ Recent data also suggested a role of IL-36 and IL-36R in dendritic cell-T cell interaction. ${ }^{3}{ }^{4}$ IL-36 $\alpha$ signals through a heterodimeric complex consisting of the IL-1 receptor accessory protein (IL-1RacP) and IL-36R. Towne et al demonstrated that IL-36 $\alpha$ activates NF- $\mathrm{kB}$ via MAPKs and signals through binding to the IL-36R. In vitro assays showed that the pro-inflammatory stimulus of IL-36 $\alpha$ was antagonised by IL-36Ra used in 100-1000-fold excess. ${ }^{4}$ Importantly, IL-36 $\alpha$ has pro-inflammatory properties and appears to play an important role in the pathogenesis of psoriasis. ${ }^{6}$ Patients with a functional deficiency in the $I L-36 R n$ gene encoding for the antagonist IL-36Ra suffer from severe generalised pustular psoriasis. ${ }^{7}$ IL-36 $\alpha$ is able to up-regulate IL-17A, IL-23 and tumour necrosis factor $\alpha$ (TNF- $\alpha),{ }^{8}$ building a pro-inflammatory network with potentially pathogenic self-perpetuation in psoriatic arthritis (PsA). Additionally, the aforementioned cytokines in turn stimulate IL-36 $\alpha$ production. ${ }^{8}$

Approximately $6-20 \%$ of psoriasis patients develop PsA; TNF- $\alpha$ as well as IL-17 are considered to play a pivotal role in PsA similar to rheumatoid arthritis (RA). ${ }^{9}$ The majority of patients with PsA and RA benefit from cytokine blocking therapies, however despite novel developments, subgroups of patients do not respond to therapy. Thus more insights into the pathogenesis of synovitis in PsA and RA are needed to understand the complex cellular interplay for developing new therapy approaches. Since IL-36 $\alpha$ and IL-36Ra play a crucial role in PsA, we hypothesised that the IL-36 family members IL-36 $\alpha$, IL-36R and IL-36Ra are also expressed in the synovial tissue of PsA patients and possibly also in that of RA and osteoarthritis $(\mathrm{OA})$ patients.

\section{MATERIAL AND METHODS \\ Patient material}

Synovial tissue was derived from knee joints of patients with RA $(n=29)$, PsA $(n=17)$ and OA $(n=22)$ obtained in three different centres (Academic Medical Center Amsterdam, University Clinic of Pavia and University Hospital of Erlangen-Nuremberg; for patient characteristics, see online supplementary text file and table S1). All samples were fixed in formalin and embedded in paraffin. All patients gave written informed consent, and their use for research was approved by the respective ethics committees of the Universities of Amsterdam, Pavia and Erlangen.

\section{Immunohistochemistry and immunofluorescence}

Sections $(2 \mu \mathrm{m})$ were stained according to immunohistochemistry (IHC) and immunofluorescence protocols, which have been described previously. ${ }^{10}$ 
As detection antibody we used rabbit anti-human IL-36 $\alpha$, antihuman IL-36Ra or anti-human IL-36R (all Atlas Antibodies). For double staining, mouse anti-human CD138 (AbDSerotec) was used. IHC sections were analysed by two blinded observers using a four-point scale (0-3) as described previously. ${ }^{11}$ The individual readings were either consistent or differed by only one point. Minor differences were resolved by mutual agreement or the mean score of two scores was used.

\section{Western blot analysis}

Synovial tissue samples were homogenised in RIPA buffer using precellys ceramic kit tubes (Peqlab); the lysates were cleared by centrifugation. Protein extracts (10-20 $\mu \mathrm{g}$ per lane) were separated on a $12 \%$ SDS-polyacrylamide gel. The membranes were probed with the following antibodies: goat polyclonal anti-IL-1F6 (R\&D System), rabbit polyclonal anti- $\beta$-actin (Sigma-Aldrich), rabbit polyclonal anti-phospho-p38, mouse monoclonal anti-phospho-IкB $\alpha$ and rabbit monoclonal anti-GAPDH (Cell Signaling). Membrane development was achieved using the enhanced chemiluminescence method (Thermoscientific).

\section{Fibroblast-like synoviocytes stimulation}

Fibroblast-like synoviocytes (FLS) (passage 2-4) isolated from arthritis patients as previously described ${ }^{12}$ (see online supplementary text) were stimulated with recombinant human IL-36 $\alpha$ (R\&D systems) for $24 \mathrm{~h}$. mRNA expression of IL-6 (5'-CGAGCCCACCGGGAACGAAA-3', 5'-GGACCGAAGGCGC TTGTGGAG-3'), IL-8 (5'-TGACTTCCAAGCTGGCCGTGG-3', 5'-CCTTGGCAAAACTGCACCTTCACA-3') and IL-36R (5'-CT GGACAAGCCGTGGCCAATGT-3', 5'-AGCCCAGCGATTCGG GGACC-3') was measured by real time PCR with GAPDH as control (all Life Technologies). Culture medium was investigated for IL-6, IL-8 and TNF- $\alpha$, by a bead based immunoassay (eBioscience). For immunoblotting, FLS were incubated for up to $30 \mathrm{~min}$; total cell lysates were stained for phospho-p38 and phospho-IкB $\alpha$.

\section{Statistical analysis}

Differences between groups were evaluated by the MannWhitney test using graph Pad Prism 4 software. We applied the Bonferroni correction for multiple testing. Group differences were considered statistically significant when the $p$ value was less than 0.05 .

\section{RESULTS \\ IL-36 $\alpha$ is up-regulated in the synovial tissue of patients with PsA and RA compared to $0 A$}

To evaluate IL-36 $\alpha$ expression in the synovium of RA, PsA and $\mathrm{OA}$ patients, synovial tissue samples were examined by IHC and western blot analysis. IL-36 $\alpha$ protein expression corresponding to a specific $17 \mathrm{kDa}$ band was detected in PsA and RA patients by immunoblotting (figure 1A). Furthermore, strong cytoplasmic expression of IL-36 $\alpha$ was found in PsA and RA patients and in some of the samples of $\mathrm{OA}$ patients (figure $1 \mathrm{~B}$ ). Expression of IL-36 $\alpha$ was partially observed in leukocytic infiltrates as well as in the lining layers. The semiquantitative analysis of IHC revealed a significantly higher expression of IL-36 $\alpha$ in RA and PsA than in OA (figure 1C, $p<0.0005$ and $p=0.0011$, respectively). IL-36 $\alpha$ expression in OA was particularly found in samples which showed signs of inflammatory infiltrates (inflamed $\mathrm{OA}$ ) compared to joints without signs of inflammation (non-inflamed $\mathrm{OA}$ ).

\section{IL-36Ra and IL-36R are expressed in patients with inflammatory arthritis}

To address whether the different expression in RA and PsA compared to OA is specific for IL-36 $\alpha$, we also investigated the expression of IL-36R and its antagonist IL-36Ra in the synovial tissue of RA, PsA and OA. We observed strong staining for both IL-36R and IL-36Ra not only in RA and PsA but also in OA synovial tissue (figure 2A,B). IL-36R and IL-36Ra were mainly expressed in leukocytic infiltrates as well as the lining layer, corresponding to the expression of IL-36 $\alpha$. Isotype control staining was completely negative (figure 2C). Quantification of tissue expression did not demonstrate any significant differences in the expression of IL-36Ra and IL-36R among the various types of arthritides (figure 2D).

\section{Synovial plasma cells are the major source for IL-36a expression in inflammatory arthritis}

Next, we sought to determine the cellular source of IL-36 $\alpha$ expression in arthritis and established double immunofluorescence labelling for IL-36 $\alpha$, IL-36R and IL-36Ra, as well as for cell specific markers. As IL-36 $\alpha$ positive cells were strongly associated with leukocytic infiltrates, we tested B cell lineage markers for co-expression. Despite sporadic co-expression of IL-36 $\alpha$ with B cells stained with CD20 (see online supplementary figure S1) the main cellular source of IL-36 $\alpha$ was CD138-positive plasma cells (figure $3 \mathrm{~A}, \mathrm{~B}$ ). In contrast, the IL-36R showed hardly any co-localisation with the plasma cells (data not shown), whereas IL-36Ra was also found to be co-localized with plasma cells in the synovial membrane (figure $3 \mathrm{D}$ ).

\section{IL-36 $\alpha$ induces cytokine production in FLS}

Our findings showed that IL-36R is expressed in FLS, as previously shown by Gabay et $a l^{3}$ To examine whether IL-36 $\alpha$ induces the expression of pro-inflammatory cytokines in FLS, we stimulated these cells with different concentrations of IL-36 $\alpha$. Expression of IL-36R was constitutive and not induced by IL-36 $\alpha$ (figure $4 \mathrm{~A}$ ). Importantly, IL-36 $\alpha$ induced mRNA expression as well as secretion of IL- 6 and IL-8, very likely triggered by $\mathrm{p}-38$ and $\mathrm{I} \kappa \mathrm{B} \alpha$ activation (figure $4 \mathrm{~B}, \mathrm{D}, \mathrm{E}$ ), suggesting that IL-36 $\alpha$ induces an inflammatory response in FLS. We did not detect any inducible expression of TNF- $\alpha$ when FLS were stimulated with IL-36 $\alpha$ (figure 4C). Additionally, the amount of cytokine production induced by IL-36 $\alpha$ was consistent with that induced by IL- $1 \beta$ but time-delayed for IL- 6 (see online supplementary figure S3). Further, IL-36 $\alpha$ did not affect the proliferation of FLS (see online supplementary figure S2B,C).

\section{DISCUSSION}

Our data show that the novel cytokine IL-36 $\alpha$ is up-regulated in the synovial tissue of patients with PsA and RA compared to OA patients. In contrast, the receptor for IL-36 $\alpha$ (IL-36R) as well as the natural antagonist of IL-36 $\alpha$ (IL-36Ra) is equally expressed throughout all three arthropathies. Up-regulation of IL-36 $\alpha$ is particularly linked to the presence of inflammatory infiltrates in the synovial tissue, which is a consistent finding in patients with both PsA and RA and is also found in some patients with $\mathrm{OA}$. Indeed, synovial tissues of $\mathrm{OA}$ patients with signs of inflammation also showed up-regulation of IL-36 $\alpha$ expression, which is consistent with the occurrence of immune cells in the synovial membrane of some OA patients. ${ }^{13}$ These findings suggest that IL-36 $\alpha$ is a cytokine which is closely linked to inflammatory processes and expressed when leukocyte infiltration is observed in affected organs. Earlier data showing 
A

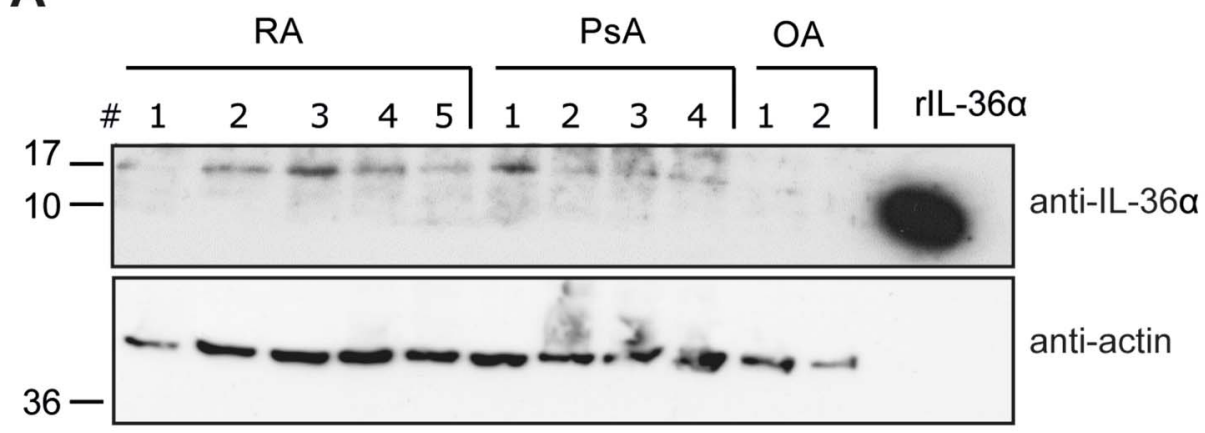

B

RA

PsA

$\mathrm{OA}$
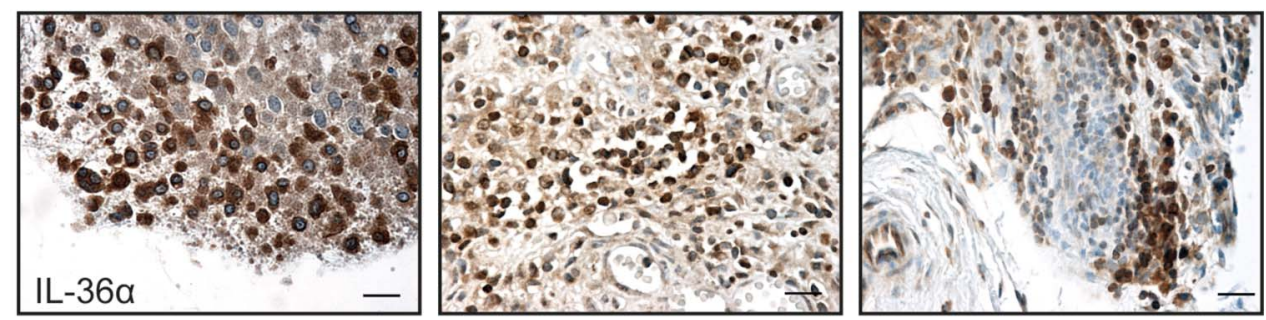

C
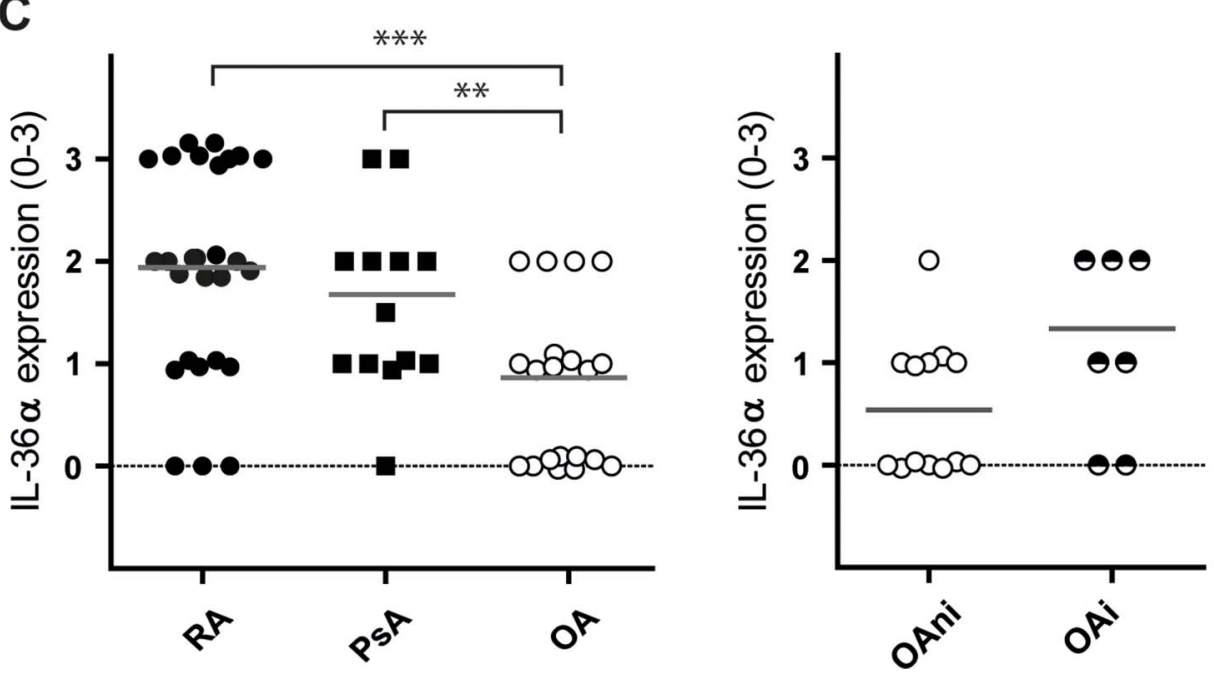

Figure 1 Interleukin (IL)-36 $\alpha$ is up-regulated in rheumatoid arthritis (RA) and psoriatic arthritis (PsA) as compared to osteoarthritis (OA). (A) Immunoblot analysis of IL-36 $\alpha$ in synovial tissue extracts of RA, PsA and OA patients. Numbers indicate individual patients. Positive control: 10 ng recombinant IL-36 $\alpha$ (rlL-36 $\alpha$ ). Actin serves as loading control. Size in kDa. (B) Synovial tissue sections were immunostained of IL-36 $\alpha$ (brown staining). Representative sections from RA (left), PsA (middle) and OA (right) are shown. Magnification 40×, scale bar $20 \mu \mathrm{m}$. (C) Quantification of immunostaining. Left: comparison of results from synovial tissue of RA, PsA and OA patients. RA, black circles $(n=31)$, PsA, black squares $(n=17)$, $0 A$, open circles $(n=22)$. Right: comparison between inflammatory and non-inflammatory $0 A .{ }^{* *} p<0.0005,{ }^{* *} p=0.0011$.

that IL-36 $\alpha$ promotes the expression of proinflammatory cytokines further support this concept. ${ }^{8}$

The link to inflammatory infiltrates is specific for IL-36 $\alpha$, but not for the IL-36R and its antagonist IL-36Ra. Thus, no difference for IL-36R and IL-36Ra was observed among the different types of arthritides. A recent study by Dinarello et al revealed a new function of IL-38, another IL-1 family member (IL-1F10). IL-38 shares amino acid sequence homology with IL-36Ra. Similar to IL-36Ra, IL-38 inhibits IL-17 and IL-22 production by $\mathrm{T}$ cells activated by Candida species. ${ }^{14}$ Since antibodies for IL-38 are not available, it is unfortunately not possible to evaluate IL-38 expression in arthritis. In our study, we did not observe any difference in IL-36Ra expression. However, recently described mutations in IL-36Ra resulting in a decreased ability to block IL-36 $\alpha$ might also be found in PsA as was previously described for pustular psoriasis. ${ }^{715}$

IL-36 $\alpha$ expression was shown by a variety of cells, including keratinocytes, $\mathrm{T}$ and $\mathrm{B}$ lymphocytes as well as monocytes. ${ }^{2}$ Therefore, we were interested in determining the cellular source of IL-36 $\alpha$ in the inflamed joint and identified plasma cells as the key cellular source of IL-36 $\alpha$ in arthritis (figure 5). We confirmed expression in other cell types such as B cells and $\mathrm{T}$ cells (see online supplementary figure $\mathrm{S} 1$ ). This finding is interesting since IL-36 $\alpha$ may function as a key link between autoimmunity, represented by plasma cells infiltrating the synovium, and inflammatory responses. 
A
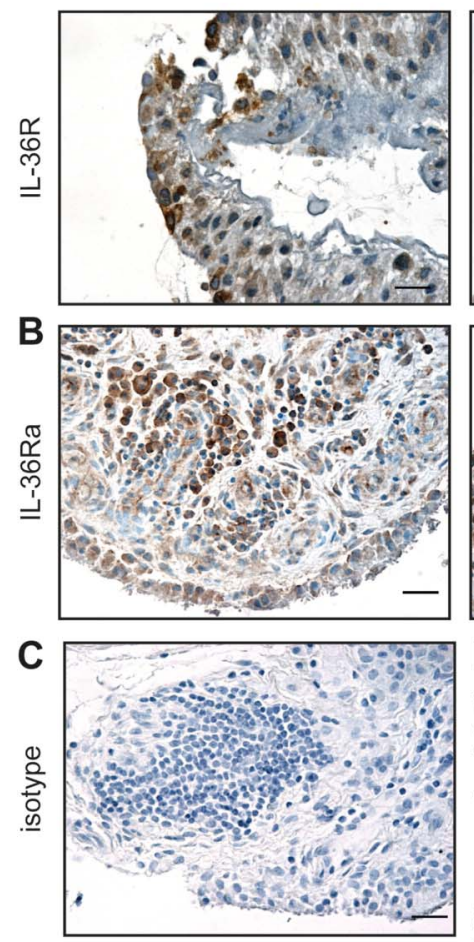

PSA
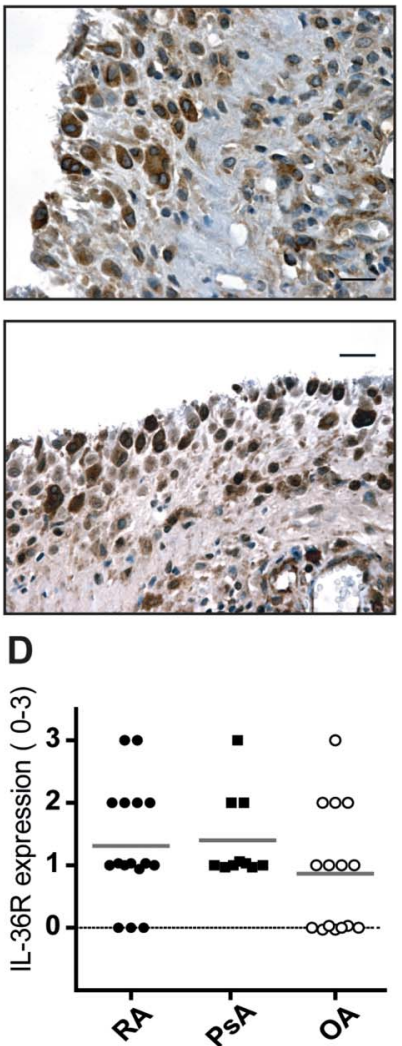

OA
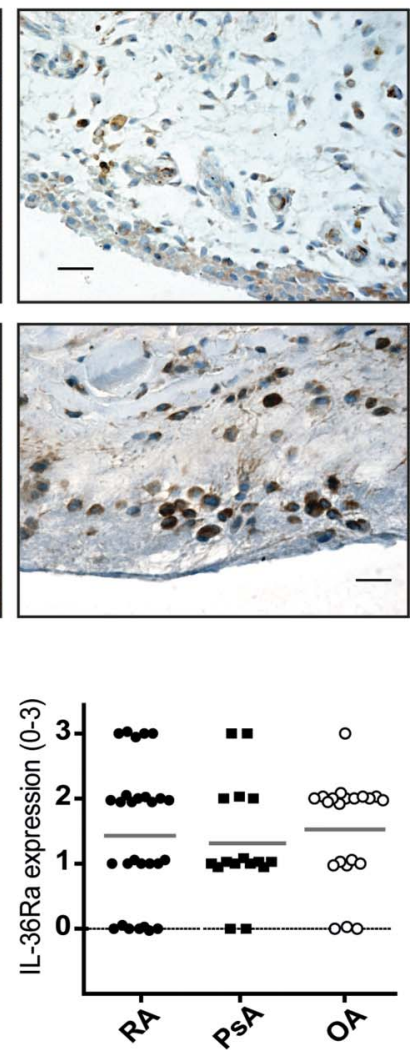

Figure 2 Interleukin-36 receptor (IL-36R) and IL-36 receptor antagonist (IL-36Ra) are consistently expressed in arthritis. Synovial tissue sections (more than 10 patients each) were immunostained for (A) IL-36R and (B) IL-36Ra. Representative sections of rheumatoid arthritis (RA) (left), psoriatic arthritis (PsA) (middle) and osteoarthritis (OA) (right) are shown. Magnification 40×, scale bar $20 \mu \mathrm{m}$. (C) Isotype control staining. (D) Immunohistochemistry for IL-36R and IL-36Ra was scored using semiquantitative analysis of protein expression ranging from 0 to 3 . IL-36R: RA $(n=16), \operatorname{PsA}(n=10), O A(n=15)$; IL-36Ra: RA $(n=28), \operatorname{PsA}(n=16), 0 A(n=21)$. Single samples and mean are shown.
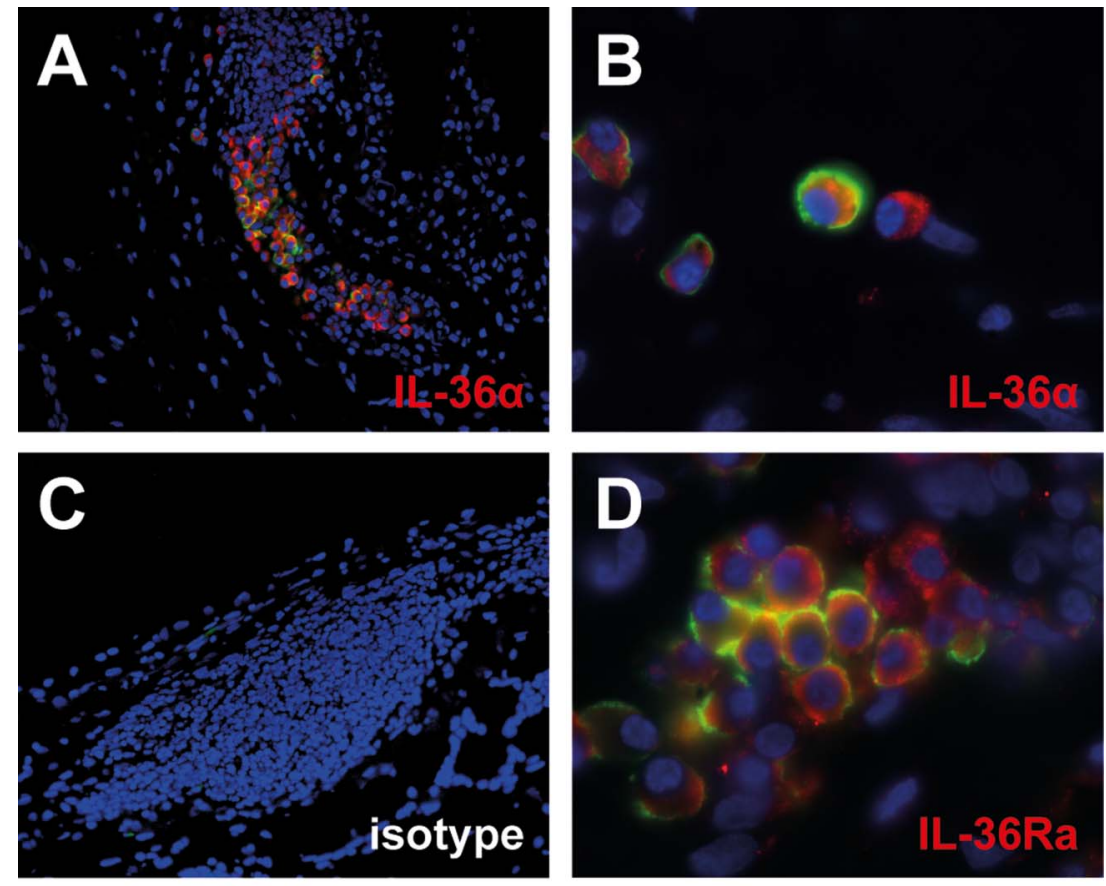

20x

$100 x$

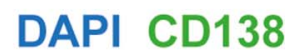

Figure 3 Synovial plasma cells are a source of interleukin-36 $\alpha$ (IL-36 $\alpha)$ expression in arthritis. Double staining immunofluorescence for (A, B) IL-36 $\alpha$ (red) and CD138 (green) in rheumatoid arthritis synovium adjusted for (C) isotype control. Magnification: (A, C) 20×, (B, D) 100×. (D) Double staining immunofluorescence for IL-36R receptor antagonist (red) and CD138 (green). Blue counterstain with DAPI. 
A

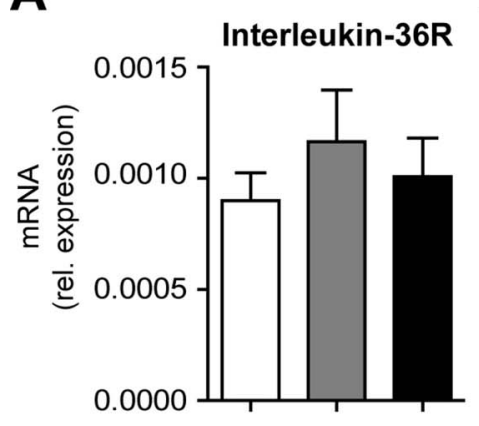

B

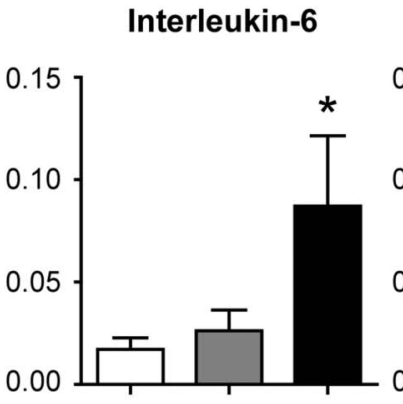

Interleukin-8

C
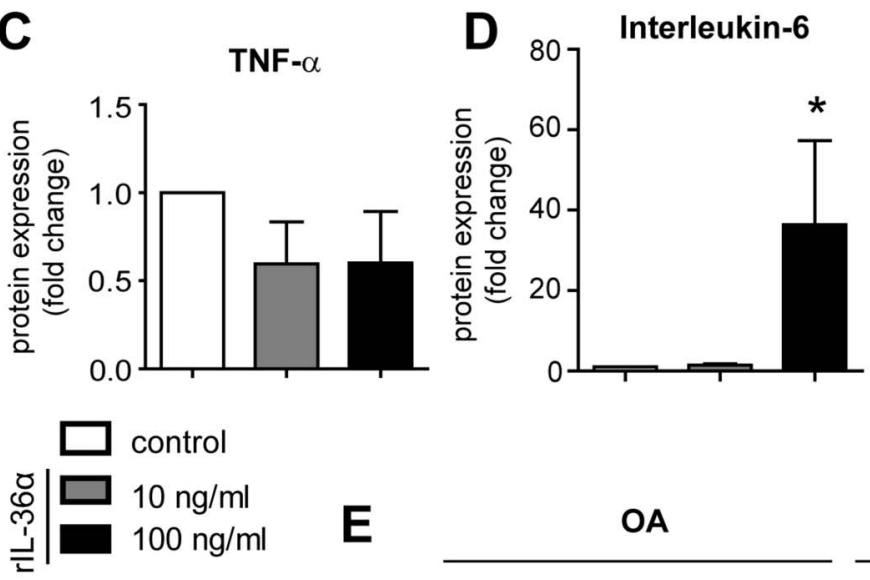

TNF- $\alpha$

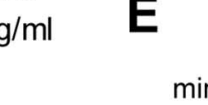

Interleukin-8

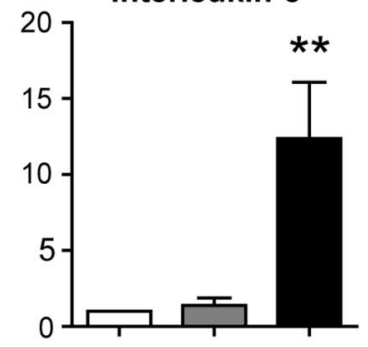

OA

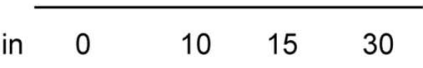

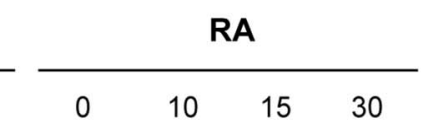

p-p38 (42kDa)

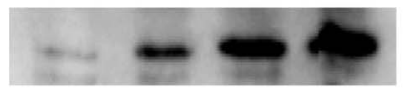

p-IKBa (40kDa)

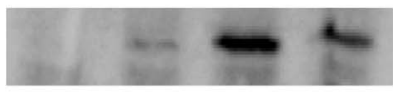

GAPDH (37kDa)

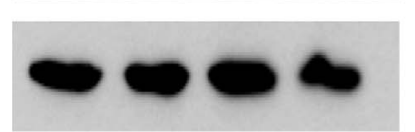

Figure 4 Interleukin-36 $\alpha$ (IL-36 $\alpha$ ) stimulates cytokine and chemokine expression by fibroblast-like synoviocytes (FLS). (A) Relative mRNA expression of IL-36R in FLS (pool of osteoarthritis $(0 A)(n=3)$, rheumatoid arthritis $(R A)(n=2)$ and psoriatic arthritis $(n=1)$ FLS) stimulated with increasing concentrations of recombinant IL-36 $\alpha$ for $24 \mathrm{~h}$. (B) Relative mRNA expression of IL-6 and IL-8 in accordance with the experimental set-up in (A). Concentration of (C) tumour necrosis factor $\alpha$ and (D) IL-6 and IL-8 in the supernatants of FLS stimulated with increasing concentrations of recombinant IL-36 $\alpha$ for $24 \mathrm{~h}$. Values are mean \pm SEM derived from triplicate measurements of at least three independent experiments. (E) Immunoblot analysis for phospho-p38 and phospho-I $\mathrm{KB} \alpha$ in FLS (OA and RA) stimulated with IL-36 $\alpha$ for indicated time points. GAPDH serves as loading control.

Considering that autoantibody formation clearly precedes the onset of clinical synovitis in RA, one could speculate that plasma cells may contribute to the progression of the inflammatory response in the joint, which requires communication between plasma cells and resident FLS. Production of IL-36 $\alpha$ by plasma cells acting on the IL-36R expressed on FLS may be one possible mechanism. This concept is supported by data demonstrating that IL-36 $\alpha$ triggers cytokine production by FLS. Since fibroblasts also express IL-36 $\alpha$ as well as IL-36Ra, a weak autocrine effect might account for the cytokine stimulation (see online supplementary figure S2A). Studies by Gabay et al have shown that IL-36 $\beta$ induces the production of IL- 6 by FLS. ${ }^{3}$ Our study extended this notion by showing that IL-36 $\alpha$ elicits a significant up-regulation of IL- 6 and IL- 8 FLS. This represents a major proinflammatory trigger since IL- 6 stimulates the synthesis of TNF- $\alpha$ and IL- 8 acts as a major chemoattractant molecule for further leukocyte migration into the joint.

In summary, our data suggest a novel mechanism by which plasma cells can interact with resident FLS in inflammatory arthritis. IL-36 $\alpha$ may be a crucial link between adaptive immune responses and autoimmunity as well as inflammatory responses in the synovium in both RA and PsA. Little is yet known about the biological function of IL-36 $\alpha$ and its relevance for human diseases. For instance, IL-36 $\alpha$ and IL-36Ra require processing of $\mathrm{N}$-terminal amino acids to increase biological activity and it is yet to be determined if these truncations are relevant in vivo. ${ }^{16}$ Its expression pattern in synovial plasma cells and its effects on cytokine and chemokine expression by synovial cells suggest that IL-36 $\alpha$ links adaptive immune responses to synovial inflammation in human arthritis. 


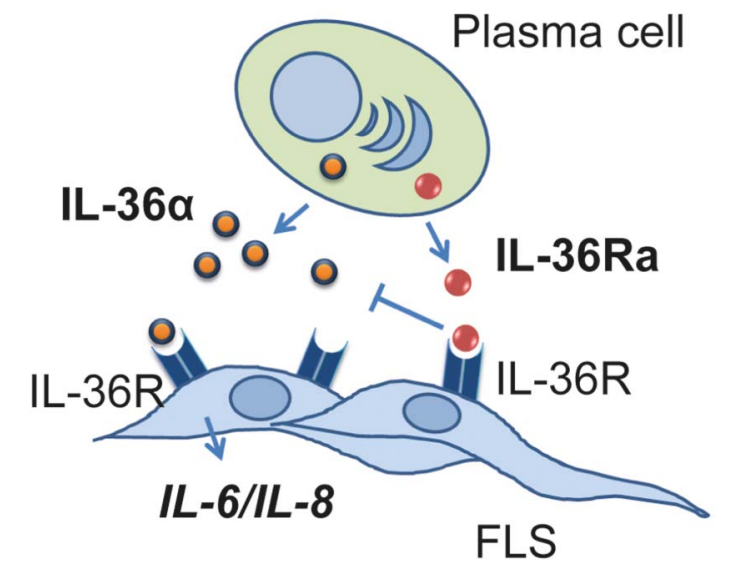

Figure 5 Schematic mode of action of interleukin-36 $\alpha$ (IL-36 $\alpha$ ) in inflammatory arthritis. IL-36 $\alpha$ and IL-36 receptor antagonist (IL-36Ra) are expressed by synovial plasma cells and engage the IL-36 receptor (IL-36R) on fibroblast-like synoviocytes (FLS), triggering the release of IL-6 and IL-8. IL-36Ra modifies this process by interfering with IL-36 $\alpha$ / IL-36R interaction.

Acknowledgements The authors express their gratitude to the donors for participating in this study. Special thanks are extended to Eugenia Scheffler and Barbara Happich for technical assistance as well as to Dr Pauser, Dr Bernd Swoboda (Waldkrankenhaus Erlangen), Dr Distler (University Hospital Erlangen) and Dr Teitsma (AMC) for the supply of arthritis samples.

Contributors SF, AJH and GS designed the study. SF, AJH, AD and MEM performed the experiments. DLPB, SB and CM gathered and provided the samples. SF, GS and AJH wrote the manuscript. All critically read, discussed and revised the manuscript.

Funding This project was supported by the ELAN fund $(A H, 11.10 .27 .1)$ of the University Hospital of Erlangen, the Masterswitch and Team Projects of the European Union and the IMI funded project BTCure.

\section{Competing interests None.}

Ethics approval Ethics committees of Universities of Erlangen, Pavia and Amsterdam.

Provenance and peer review Not commissioned; externally peer reviewed.
Correction notice This article has been corrected since it was published Online First. All instances of "leucocyte" and "leucocytic" have been changed to "leukocyte" and "leukocytic" respectively.

\section{REFERENCES}

1. Dinarello C, Arend W, Sims J, et al. IL-1 family nomenclature. Nat Immunol 2010:11:973

2. Smith DE, Renshaw BR, Ketchem RR, et al. Four new members expand the interleukin-1 superfamily. J Biol Chem 2000;275:1169-75.

3. Magne D, Palmer G, Barton JL, et al. The new IL-1 family member IL-1F8 stimulates production of inflammatory mediators by synovial fibroblasts and articular chondrocytes. Arthritis Res Ther 2006;8:R80.

4. Vigne S, Palmer G, Lamacchia C, et al. IL-36R ligands are potent regulators of dendritic and T cells. Blood 2011;118:5813-23.

5. Towne JE, Garka KE, Renshaw BR, et al. Interleukin (IL)-1F6, IL-1F8, and IL-1F9 signal through IL-1Rrp2 and IL-1RAcP to activate the pathway leading to NF-kappaB and MAPKs. J Biol Chem 2004;279:13677-88.

6. Blumberg H, Dinh $\mathrm{H}$, Trueblood ES, et al. Opposing activities of two novel members of the IL-1 ligand family regulate skin inflammation. J Exp Med 2007;204:2603-14

7. Marrakchi S, Guigue P, Renshaw BR, et al. Interleukin-36-receptor antagonist deficiency and generalized pustular psoriasis. N Engl J Med 2011:365:620-8.

8. Blumberg $\mathbf{H}$, Dinh H, Dean C Jr, et al. IL-1RL2 and its ligands contribute to the cytokine network in psoriasis. J Immunol 2010;185:4354-62.

9. Hueber AJ, McInnes IB. Immune regulation in psoriasis and psoriatic arthritisrecent developments. Immunol Lett 2007;114:59-65.

10. Hueber AJ, Asquith DL, Miller AM, et al. Mast cells express IL-17A in rheumatoid arthritis synovium. J Immunol 2010;184:3336-40.

11. Smeets TJ, Dolhain RJ, Breedveld FC, et al. Analysis of the cellular infiltrates and expression of cytokines in synovial tissue from patients with rheumatoid arthritis and reactive arthritis. J Pathol 1998;186:75-81.

12. Zimmermann $\mathbf{T}$, Kunisch $E$, Pfeiffer $R$, et al. Isolation and characterization of rheumatoid arthritis synovial fibroblasts from primary culture-primary culture cells markedly differ from fourth-passage cells. Arthritis Res 2001;3:72-6.

13. Bondeson J, Blom AB, Wainwright $\mathrm{S}$, et al. The role of synovial macrophages and macrophage-produced mediators in driving inflammatory and destructive responses in osteoarthritis. Arthritis Rheum 2010;62:647-57.

14. van de Veerdonk FL, Stoeckman AK, Wu G, et al. IL-38 binds to the IL-36 receptor and has biological effects on immune cells similar to IL-36 receptor antagonist. Proc Natl Acad Sci USA 2012;109:3001-5.

15. Onoufriadis A, Simpson MA, Pink AE, et al. Mutations in IL36RN/L1F5 are associated with the severe episodic inflammatory skin disease known as generalized pustular psoriasis. Am J Hum Genet 2011;89:432-7.

16. Towne JE, Renshaw BR, Douangpanya J, et al. Interleukin-36 (IL-36) ligands require processing for full agonist (IL-36alpha, IL-36beta, and IL-36gamma) or antagonist (IL-36Ra) activity. J Biol Chem 2011:286:42594-602. 


\section{A The novel cytokine interleukin-36 $\alpha$ is expressed in psoriatic and rheumatoid arthritis synovium}

Silke Frey, Anja Derer, Maria-Elena Messbacher, Dominique L P Baeten, Serena Bugatti, Carlomaurizio Montecucco, Georg Schett and Axel J Hueber

Ann Rheum Dis 2013 72: 1569-1574 originally published online December 25, 2012

doi: 10.1136/annrheumdis-2012-202264

Updated information and services can be found at:

http://ard.bmj.com/content/72/9/1569

These include:

Supplementary Material

References

Email alerting service
Supplementary material can be found at:

http://ard.bmj.com/content/suppl/2013/08/06/annrheumdis-2012-2022 64.DC1.html

This article cites 16 articles, 8 of which you can access for free at: http://ard.bmj.com/content/72/9/1569\#BIBL

Receive free email alerts when new articles cite this article. Sign up in the box at the top right corner of the online article.

Topic
Collections

Articles on similar topics can be found in the following collections

Immunology (including allergy) (5117)

Degenerative joint disease (4621)

Musculoskeletal syndromes (4930)

Connective tissue disease (4234)

Rheumatoid arthritis (3245)

Osteoarthritis (929)

\section{Notes}

To request permissions go to:

http://group.bmj.com/group/rights-licensing/permissions

To order reprints go to:

http://journals.bmj.com/cgi/reprintform

To subscribe to BMJ go to:

http://group.bmj.com/subscribe/ 